\title{
Knowledge management practices at an institution of higher learning
}

\author{
Authors: \\ Judith Mavodza ${ }^{1}$ \\ Patrick Ngulube 2 \\ Affiliations: \\ ${ }^{1}$ Zayed University Library, \\ Zayed University, Abu Dhabi \\ ${ }^{2}$ Department of \\ Interdisciplinary Research, \\ College of Graduate Studies, \\ University of South Africa, \\ South Africa \\ Correspondence to: \\ Patrick Ngulube \\ Email: \\ ngulup@unisa.ac.za \\ Postal address: \\ PO Box 392, UNISA 0003, \\ South Africa \\ Dates: \\ Received: 15 Aug. 2011 \\ Accepted: 10 Aug. 2012 \\ Published: 05 Oct. 2012 \\ How to cite this article: \\ Mavodza, J. \& Ngulube, \\ P., 2012, 'Knowledge \\ management practices at an \\ institution of higher learning', \\ SA Journal of Information \\ Management 14(1), Art. \\ \#496, 8 pages. http://dx.doi. \\ org/10.4102/sajim.v14i1.496
}

(C) 2012. The Authors. Licensee: AOSIS OpenJournals. This work is licensed under the Creative Commons Attribution License.
Background: This article underscores the fact that society is becoming more and more knowledge-based, and that the organisations that can identify, value, create and evolve their knowledge assets are likely to be more successful than those that do not. Knowledge management $(\mathrm{KM})$ is about enhancing the use of organisational knowledge through sound practices of $\mathrm{KM}$ and organisational learning. KM practices encompass the capture and/or acquisition of knowledge, its retention and organisation, its dissemination and re-use, and lastly responsiveness to the new knowledge.

Objective: The focus of this study was on KM principles and practices that may be in place in the Metropolitan College of New York (MCNY). The argument is that KM and its survival principles and tools may help the College to improve performance. However, there is uncertainty about whether the use of KM principles and tools can partly solve the College's approach to improving the quality of education it provides.

Methods: A mixed methods research methodology encompassing a questionnaire, observation, interviews, and use of institutional documents was used in the investigation.

Results: The findings of the study indicate that KM concepts were not universally understood at MCNY.

Conclusion: There is a need to create a knowledge inventory at MCNY. This may help the College to develop appropriate institution-wide policies and practices for proper and well organised methods of integrating work processes, collaborating and sharing (including the efficient use of social media), and developing an enabling institutional culture.

\section{Introduction}

Society has become more and more knowledge-based. Therefore the organisations that can identify, value, create and evolve their knowledge assets are likely to be more successful than those that do not. Knowledge in a modern organisation is an essential resource especially because it is not readily replicated by rivals. Jain (2007) and Senge (1994) point out that some organisations are unable to function as knowledge-based organisations because they have learning disabilities. It is important for an organisation to have a clear understanding of what knowledge management (KM) means to its operations if it needs to consider using those KM practices that enhance efficiency and lend value to organisational knowledge. In this way knowledge becomes a strategic resource (Kok 2012).

These practices include knowledge generation, which encompasses activities that bring to light all the knowledge that is new to a group or to an individual. Knowledge generation comprises the exploitation of existing knowledge to create new knowledge, as well as finding new knowledge through interacting and collaborating with other individuals or systems (Nonaka 1991; Nonaka \& Takeuchi 1995; Nonaka \& Teece 2001). This process therefore involves the acquisition of knowledge if it is to be successful. The acquired knowledge is of limited value if it is not organised and stored for easy retrieval. Once it is available for retrieval, there is a need to have systems that enable its sharing and transfer. A process of knowledge retention results when an organisation is able to facilitate the capture and transfer of both formal and informal knowledge through knowledge networking, thereby using the available intellectual capital to its advantage.

As an academic institution, the Metropolitan College of New York (MCNY) operates in the new knowledge-based information environment that is characterised by radical and discontinuous changes. This carries a new mandate for knowledge creation and implementation in order to get benefits that are at the core of its education mission. Preparing students to meet the needs of today's society is one of the direct benefits of the use of KM practices. In this perspective, the main challenge for MCNY is to develop and implement KM processes in order to make its educational mission relevant to society. The challenge coincides with the concern raised by 
Cohen (1989), the founder of the College, who expressed the sentiment that knowledge at the College was organised to encourage its practical application in human service practice and performance. This article aims to discuss the concepts, tools, processes and requirements of KM practices and their relevance to reaching the goal of quality education at MCNY.

\section{Types of knowledge and knowledge management}

As do many higher education environments, MCNY possesses explicit knowledge in the form of financial records necessary for meeting tax, payroll or accounting obligations, files of important historical documents, self-study documents, research articles, conference proceedings, and minutes of meetings. Photo albums and similar mementos of college activities and interests form part of the knowledge asset, as well as library databases. Townley (2001) points out that research and scholarship are the tangible assets of an academic institution. In addition to these tangible explicit knowledge assets there are the tacit or implied knowledge and human expertise of the people who work in the organisation, as well as everything that is contained in the intranets.

$\mathrm{KM}$ facilitates the utilisation and integration of tacit and explicit knowledge. It emphasises 'collaborative learning, the capture of tacit knowledge, and value-add obtained through best practices and data mining' (Gandhi 2004:373). Rowley (2003), Singh (2007), and Wen (2005) highlight the fact that $\mathrm{KM}$ encompasses both the management of people and of information. On the other hand, Barquin (2001) describes $\mathrm{KM}$ as a process with phases and components, embedded in time. There is more than one approach to this process; it has different structures and architectures, and there are expected outcomes and performance to be measured. Concurring with this view, Kok (2012) also points out the importance of identifying ownership and the source of knowledge, and providing mechanisms and incentives for sharing knowledge without possessiveness. The same point is expressed by Singh (2007:172) who is also of the view that KM 'implies the process of transforming information and intellectual assets into enduring value'. In practice this leads to a process of the interpreting and utilising of collective intelligence by a community of participants.

KM practices in higher education are actions aimed at improving the internal flow and use of information through knowledge acquisition and knowledge sharing for institutional effectiveness (Kidwell, Vander Linde \& Johnson 2000; Williams et al. 2004). From the definitions given, it appears that $\mathrm{KM}$ is a process that enables an organisation to improve its performance by enabling learning and innovation whilst solving its problems, acknowledging and resolving gaps in its operations, and recognising knowledge (comprising people and information) as an organisational asset which has to be managed through enabling policies and institutional tools.

\section{The knowledge management process and flow}

Recognising knowledge as an asset and using it creatively does not always occur in an obvious manner. Nonaka and Takeuchi (1995) suggest that knowledge is transferred from one form to another because of a continuous process of interaction between tacit and explicit knowledge in an organisation. The result is the ability to create new knowledge which has economic worth and is essential for innovation. For this to take place, a space called $\mathrm{Ba}$ (Nonaka \& Konno 1998), where knowledge is created and shared through social media, is needed. According to Nonaka and Konno (1998):

$B a$ can be thought of as a shared space for emerging relationships. This space can be physical (e.g., office, dispersed business space), virtual (e.g., e-mail, teleconference), mental (e.g., shared experiences, ideas, ideals), or any combination of them. What differentiates $B a$ from ordinary human interaction is the concept of knowledge creation. $\mathrm{Ba}$ provides a platform for advancing individual and/or collective knowledge. It is from such a platform that a transcendental perspective integrates all information needed. $B a$ may also be thought of as the recognition of the self in all. According to the theory of existentialism, $B a$ is a context which harbors meaning. Thus, we consider $B a$ to be a shared space that serves as a foundation for knowledge creation. (p. 40)

This explanation suggests that spaces are $B a$ and each knowledge conversion mode is associated with its own $\mathrm{Ba}$. Identifying and using the spaces as well as consciously operating in the knowledge conversion mode supports the evolving needs of a typical educational establishment to benefit from its knowledge capital. However, Chou and $\mathrm{He}$ (2004) point out that they do not find a comprehensive and feasible model that delineates the interrelationships between knowledge assets, and that knowledge creation processes are absent.

It may well be that the concern raised by Chou and He (2004) will be resolved by means of systematic and repeated studies of actual practice. The potential and environment to capture, create and use knowledge assets were present at MCNY.

\section{Statement of the problem}

Library support at MCNY is in the form of print and online resources, reference services and information literacy classes for all library users. The library currently suffers from an inability to provide every resource and service that the students and faculty require. This is confirmed by the MCNY Self-Study (2009:51) which states that there is consensus amongst students and staff that 'library resources and services are not adequate'. The reasons are financial as well as practical. Firstly, the library cannot survive in isolation and provide everything that the College library users need. The cost of books and other information resources has become too prohibitive to cope with, so networking with other librarians and libraries for interlibrary lending and discounts when purchasing material have become essential, but are still not sufficient. Secondly, if the money were available to buy every 
book and every update and new edition on the market, space limitations would be prohibitive. The floor and shelf space at the MCNY library cannot accommodate limitless numbers of books.

Thirdly, there are now so many resources provided online that the library has to find a balance between what is available in print and what is available online. Fourthly, with staff cuts that have taken place due to a shrinking budget, it is not possible to have a robust library staff complement to give sufficient attention to individual library users' needs. Fifthly, the library is a department within the larger institution and to a large extent operates within the managerial and organisational parameters of the institution. This means that decisions that may seem best suited for the library are not necessarily acceptable unless they give advantage and enhance relevance to the institution as a whole. In addition to these challenges, a new information environment has brought additional demands. Despite the given circumstances, the library is still expected to provide a consistently efficient and effective quality service.

Following the question raised by Creswell (2007:102), 'Why is this study needed?', and the suggestions of Hernon and Schwartz (2007:307) that the statement of the problem should 'withstand a reviewer raising the "so what" question', the problem statement in this case would be that the MCNY library is providing a service that needs quality improvement as it does not adequately address challenges posed by a fast-changing information environment. However, no documented study has investigated why this is so and what needs to be done to improve the situation.

There is uncertainty about whether the use of KM principles and tools can partly solve the library's approach to improving the quality of its service to its community in the modern information environment. KM has been implemented in commercial and business environments for the sake of operational advantages and financial gains. It may be possible that KM survival principles and tools would help the library to improve its performance and fulfil its mandate. Because librarians serve users who also consume the products of the retail, entertainment and mass media industries, their efforts have become more focussed towards creating library spaces that are inviting, dynamic and exciting for the library users. These entail, amongst other things, the implementation of Web 2.0 technologies. Web 2.0 is the second generation of web-based services and tools that emphasise online sharing and collaboration amongst users. They are not KM, but can be used as tools in KM practice.

The research problem is further addressed by looking at the research questions and possible sources of data. In the process of investigating the library-related problem KM practices that are relevant to the entire College are revealed.

\section{Research questions}

Research questions are used for obtaining both qualitative and quantitative data. Specific questions that informed this research are:
- What do librarians, faculty, and administrators understand KM to mean?

- What are the knowledge needs of the MCNY community?

- What knowledge retention policies, practices and gaps are in existence at MCNY?

- What modern technologies are in use at MCNY that enhance the environment for KM practice?

- What are the tools, methods and techniques used for knowledge retention, knowledge assessment, knowledge acquisition and knowledge transfer at the MCNY library?

- What are the recommendations regarding the implementation of KM practices that will enhance the value of the library service at MCNY?

\section{Research methodology}

Regarding the MCNY library this study adopted a case study approach. Whilst Creswell (2007) and Tellis (1997) see a case study as a research methodology, Stake (2005:438) views it as 'a choice of what is to be studied'. We tend to subscribe to the latter view. The research process for this case study was conducted through the use of a questionnaire, interviews, observation, and institutional documents. A sample drawn from the MCNY employee community was used for the quantitative phase.

Survey type sample size calculation was utilised, meaning that a sample error formula, rather than the power analysis formulae that are usually utilised in experimental research, was used. The decision in selecting the random sample was to have a confidence level of $95 \%$ and a $10 \%(0.10)$ sampling error. The result was a sample of 79 individuals, that is, $17.5 \%$ of the entire MCNY employee community. On the other hand, purposive sampling was used for qualitative data collection. All usable questionnaire responses were analysed using Microsoft Excel and the SurveyMonkey online survey software and questionnaire tool. Qualitative data analysis was achieved by identifying patterns and themes in the collected study data. To make sense of them, there was need for synthesis and summary.

\section{Research results}

A summary of the major findings was organised according to the themes raised by the research questions of the study. The results emanated from the entire College, and reflected questionnaire, interview, observation, and document review findings.

Research results indicate that there was a certain degree of understanding of KM concepts at MCNY. This was reflected by the fact that in the questionnaire, when asked if information and knowledge have the same meaning, 32 $(78 \%)$ of the respondents disagreed with the notion that they mean the same thing, whilst $5(12 \%)$ did not give an opinion, and only $4(10 \%)$ agreed. The question of KM including information management had $33(80 \%)$ respondents agreeing, $5(12 \%)$ remaining ambivalent, and $3(8 \%)$ disagreeing with it. Concerning whether $\mathrm{KM}$ is the same as information management, 31 (75\%) disagreed, 6 (15\%) gave a non-committal response, and $4(10 \%)$ agreed. Amongst 
questionnaire respondents, $36(88 \%)$ agreed that knowledge depends on information, $1(2 \%)$ was ambivalent about giving an opinion, whilst $4(10 \%)$ disagreed. These perceptions are reflected in Table 1.

Four interview participants expressed an understanding of what KM refers to whilst one was unsure. Twenty per cent of the observable events during the observation phase suggested that employees were involved with activities that could be classified as enabling to KM practice. These data suggest that being aware of KM or knowing what it means does not necessarily mean practicing it. In addition, there was no mention of KM in MCNY documents or archive. The implication of these results is that in practice this study was exploratory as the use of KM appeared to be a new concept to the way job responsibilities were fulfilled.

This study was also involved in identifying the knowledge needed to support the education goals of MCNY, establishing where knowledge is stored, and highlighting gaps. Questionnaire results indicate a certain appreciation of paper-based documents, computers in departments, personal computers and a central information system as sources and locations of knowledge. This is expressed by 19 $(48 \%)$ questionnaire respondents agreeing that knowledge was found in paper-based documents, whilst $3(8 \%)$ gave no opinion, and 17 (44\%) did not agree; 17 (44\%) disagreed that knowledge was in the heads of departmental members, whilst $16(41 \%)$ chose not to give an opinion about that perception, and 6 (14\%) agreed with it.

At the same time, 25 (64\%) respondents were of the perception that the knowledge they needed to perform their job functions was on their personal computers or workstations whilst 9 $(23 \%)$ gave a non-committal response and $5(13 \%)$ disagreed. A significant number of $19(48 \%)$ did not give an opinion about knowledge being kept in a central storage space, although $10(26 \%)$ agreed and another 10 (26\%) disagreed with that perception. It was interesting to note that $12(31 \%)$ agreed, whilst $12(31 \%)$ disagreed that knowledge storage was done on all computers in the departments they worked in, and 15 (38\%) did not give an opinion. A non-committal response also seemed the most popular concerning the availability of knowledge in a central information system as indicated by $19(48 \%)$ giving no opinion, whilst 10 (26\%) agreed and $10(26 \%)$ disagreed. These perceptions are reflected in Table 2. These data point towards a need for definite information and knowledge storage capabilities. All interview participants actually suggested the desirability of creating knowledge repositories for the improvement of capturing knowledge assets that include student projects, institutional records (archival and otherwise) and conference and symposium papers. Whilst the suggested repositories suggest a gap in knowledge storage, it also brings out the desire of study participants to determine what constitutes valuable information and knowledge worth retaining as the College's institutional memory.

Establishing its knowledge needs will affect the College's strategic planning. According to Stankosky (2005) and Mavodza and Ngulube (2011), it has an impact on an
TABLE 1: Understanding of knowledge management at Metropolitan College of New York.

\begin{tabular}{|c|c|c|c|c|c|c|}
\hline \multirow[t]{2}{*}{ Level of understanding } & \multicolumn{2}{|c|}{ Agree } & \multicolumn{2}{|c|}{ Neutral } & \multicolumn{2}{|c|}{ Disagree } \\
\hline & $n$ & $\%$ & $n$ & $\%$ & $n$ & $\%$ \\
\hline $\begin{array}{l}\text { Information and knowledge mean } \\
\text { the same thing }\end{array}$ & 4 & 10 & 5 & 12 & 32 & 78 \\
\hline Knowledge depends on information & 36 & 88 & 1 & 2 & 4 & 10 \\
\hline $\begin{array}{l}\text { Knowledge management is the same } \\
\text { as information management }\end{array}$ & 4 & 10 & 6 & 15 & 31 & 75 \\
\hline $\begin{array}{l}\text { Knowledge management includes } \\
\text { information management }\end{array}$ & 33 & 80 & 5 & 12 & 3 & 8 \\
\hline
\end{tabular}

$n$, number of responses.

TABLE 2: Places where Metropolitan College of New York knowledge was stored.

\begin{tabular}{|c|c|c|c|c|c|c|}
\hline \multirow[t]{2}{*}{ Storage location } & \multicolumn{2}{|c|}{ Agree } & \multicolumn{2}{|c|}{ Neutral } & \multicolumn{2}{|c|}{ Disagree } \\
\hline & $n$ & $\%$ & $n$ & $\%$ & $n$ & $\%$ \\
\hline Paper-based documents & 19 & 48 & 3 & 8 & 17 & 44 \\
\hline Heads of department members & 6 & 14 & 16 & 41 & 17 & 44 \\
\hline Central information system & 10 & 26 & 19 & 48 & 10 & 26 \\
\hline Personal computer or workstation & 25 & 64 & 9 & 23 & 5 & 13 \\
\hline All computers in the department & 12 & 31 & 15 & 38 & 12 & 31 \\
\hline
\end{tabular}

$n$, number of responses.

organisation's ability to meet its goals and objectives, and its projection on how best to use its services and knowledge products for the future. Because these processes involve people in the organisation, there can be real barriers to their successful implementation. Some of these barriers are, for instance, the fact that KM may not necessarily be a way of doing daily business (as was the case at MCNY) and that a policy that can guide it therefore does not exist, fear of adopting new or different ways of doing things with its resulting human resistance, lack of appropriate organisational infrastructure to handle some KM practices, and the fact that KM may be deemed unsuitable for some settings.

Some respondents perceived organisational policy and/or directives as barriers that prevented them from storing information effectively: 11 (28\%) agreed with this view, even if $18(46 \%)$ gave no opinion and $10(26 \%)$ disagreed. Having a majority of respondents give a noncommittal response leaves an ambivalent interpretation, but all interview respondents were clear about the need for definite organisational directives if the MCNY working culture and environment were to change.

Whilst the MCNY use of an intranet, wikis and blogs falls into the category of $\mathrm{KM}$ tools, 21 (54\%) questionnaire respondents felt that there were no proper organisational guidelines on sharing information. Four (10\%) disagreed with that, but $14(36 \%)$ gave no opinion. The view that the bureaucratic procedures involved in sharing were complicated was expressed by $15(39 \%)$ who agreed with the statement. Seventeen (44\%) gave a non-committal response whilst $7(18 \%)$ disagreed with that perception. Perceptions on challenges in information storage are reflected in Table 3. This implied the importance of leadership at the MCNY to be cognisant of the advantages of KM practices, and to have its essentials incorporated into the organisation's strategic plan and strategic goals, as suggested by Stankosky (2005). This kind of executive support results in a KM policy that Jain (2007:379) refers to as the road map to answer 
questions about the 'what, why, how, and who' of KM, because this approach can result in systemic changes, not merely isolated changes in the operations of any single department.

This view partly concurs with the suggestion made by Singh and Kant (2008) that KM barriers include the lack of top management commitment, lack of technological infrastructure, lack of clearly defined methods or processes for KM practice, lack of an organisational structure that supports a KM strategy, lack of organisational culture, lack of motivation and rewards, staff retirement, lack of ownership of problems, and staff turnover. This reinforces the point made by Kok (2003) who writes that knowledge management practice is benchmarked by the use of enablers that include leadership, technology, culture and measurement. Despite these barriers, the modern information environment that includes a wide variety of information, information providers and platforms for doing so has made it necessary for organisations, including education institutions, to consider using $\mathrm{KM}$ tools and techniques to identify what tacit and explicit knowledge exists in the organisation, and what knowledge they might require in the future to enhance work processes.

The importance of capturing knowledge before it leaves the College, or institutional know-how, could be a priority if the need for its retention was realised. The implication of this statement is that besides the requirement to have guidelines or procedures on what knowledge to capture, it needs to be systematically organised. This is important because not all information is knowledge, and not all knowledge is valuable (Aswath \& Gupta 2009). Acquired knowledge is of limited value if it is not organised and stored for easy retrieval, as was exemplified by the absence of an organised archive at MCNY. For example, observation results indicated that the MCNY archive needed proper organisation as retrieval depended more on the memory of individuals than on a finding aid. Broadbent (1998) suggests the 'purposeful management processes which capture often personal and contextual information that can be used for the organisation's benefit'. Valuable knowledge needs to be drawn out and retained so that there is continuity even when the creator leaves the organisation, and the retrieval of knowledge is not solely dependent on individuals' memory. Eventually, a knowledge bank (Branin 2003), repository (Bailey 2005) or portal may exist. The data captured from the study are suggestive of the fact that some knowledge was retained at the MCNY but clear policies and practices for doing throughout the college needed to be clear and in place.

In this study, it was essential to establish the College's KM capacity in key areas such as the ability to recognise experts within the College, leadership, institutional work culture, and technology. It was also important to find out whether using $\mathrm{KM}$ tools and techniques would help the College meet its goals. The study was therefore ultimately aimed at determining whether the College could use and was in fact using its knowledge assets effectively and efficiently. It was revealed that MCNY, as an institution of higher learning, had experts in various academic disciplines besides those in administrative and non-administrative positions. However,
KM was not part of its institutional work culture, a fact which was reflected and demonstrated in interviews as well as in the questionnaire results. Therefore it is important to identify and describe the knowledge needs of MCNY and enumerate the variables involved in the process of recognising experts.

Whilst the lack of a proper IT platform on which to share information was seen by 16 (41\%) questionnaire respondents as a hindrance, $14(36 \%)$ gave a non-committal response, but $9(23 \%)$ disagreed with that notion (see Table 3). Kim and Abbas (2010) point to a lack of confidence on the part of potential contributors to a wiki, and sometimes a lack of clarity about how to make contributions. This was confirmed by $18(46 \%)$ questionnaire respondents who gave no opinion about colleagues' failure to perceive that there was an urgent need to share information, 12 (31\%) who agreed and $9(23 \%)$ who disagreed with that perception. Furthermore, $17(44 \%)$ gave no opinion about their own failure to realise an urgent need to share information, whilst $6(15 \%)$ agreed, but $16(41 \%)$ disagreed with that view; 15 (39\%) gave a noncommittal response about the lack of an open-minded sharing environment at MCNY, 15 (39\%) agreed, but 9 (23\%) disagreed; $12(31 \%)$ gave no opinion about the lack of trust in other people's knowledge, 16 (41\%) agreed with that perception, but $11(28 \%)$ disagreed. Some respondents felt that their tasks did not require cross-departmental information sharing; this was confirmed by 13 (33\%) who agreed, 17 (44\%) who gave no opinion and $7(18 \%)$ who disagreed. These data reflect the need and relevance of an institutional culture in information and knowledge sharing to facilitate knowledge acquisition. This view is also expressed by Kok (2012) who concludes that the use of internal and external knowledge and information can improve the process of decision making and enhance the development of innovative capacity, which will result in better effectiveness and efficiency. The discussed perceptions are demonstrated in Table 4.

TABLE 3: Challenges in storing information received more efficiently and effectively at Metropolitan College of New York.

\begin{tabular}{|c|c|c|c|c|c|c|}
\hline \multirow[t]{2}{*}{ Challenges experienced } & \multicolumn{2}{|c|}{ Agree } & \multicolumn{2}{|c|}{ Neutral } & \multicolumn{2}{|c|}{ Disagree } \\
\hline & $n$ & $\%$ & $n$ & $\%$ & $n$ & $\%$ \\
\hline $\begin{array}{l}\text { No proper organisational guidelines } \\
\text { on sharing }\end{array}$ & 21 & 54 & 14 & 36 & 4 & 10 \\
\hline $\begin{array}{l}\text { Bureaucratic procedures involved in } \\
\text { sharing are complicated }\end{array}$ & 15 & 39 & 17 & 44 & 7 & 18 \\
\hline $\begin{array}{l}\text { No proper IT platform to share } \\
\text { information }\end{array}$ & 16 & 41 & 14 & 36 & 9 & 23 \\
\hline Organisational policy and/or directives & 11 & 28 & 18 & 46 & 10 & 26 \\
\hline
\end{tabular}

$n$, number of responses.

TABLE 4: Individual challenges faced in sharing information with people from other departments within the College.

\begin{tabular}{|c|c|c|c|c|c|c|}
\hline \multirow[t]{2}{*}{ Challenges faced } & \multicolumn{2}{|c|}{ Agree } & \multicolumn{2}{|c|}{ Neutral } & \multicolumn{2}{|c|}{ Disagree } \\
\hline & $n$ & $\%$ & $n$ & $\%$ & $n$ & $\%$ \\
\hline $\begin{array}{l}\text { Colleagues do not seem to perceived } \\
\text { that there is an urgent need to share }\end{array}$ & 12 & 31 & 18 & 46 & 9 & 23 \\
\hline $\begin{array}{l}\text { I do not see an urgent need to share } \\
\text { information }\end{array}$ & 6 & 15 & 17 & 44 & 16 & 41 \\
\hline $\begin{array}{l}\text { Lack of open-minded information } \\
\text { sharing }\end{array}$ & 15 & 39 & 15 & 39 & 9 & 23 \\
\hline $\begin{array}{l}\text { Lack of trust of other people's } \\
\text { knowledge }\end{array}$ & 16 & 41 & 12 & 31 & 11 & 28 \\
\hline $\begin{array}{l}\text { My tasks do not require cross- } \\
\text { department information sharing }\end{array}$ & 13 & 33 & 9 & 23 & 17 & 44 \\
\hline $\begin{array}{l}\text { I do not know about other people's } \\
\text { knowledge needs }\end{array}$ & 18 & 46 & 13 & 33 & 8 & 21 \\
\hline
\end{tabular}

knowledge needs

$n$, number of responses. 
There may sometimes be a need to give incentives to employees to contribute to KM activities as this has been proved to be an effective way of encouraging them to be participative (Aharony 2011; Aswath \& Gupta 2009; Barquin 2001; Weddell 2008). At MCNY the kinds of incentives used included the fact that attending courses, conferences or workshops was encouraged. This was expressed by $23(59 \%)$ questionnaire respondents who agreed, whilst $10(26 \%)$ were non-committal and $6(15 \%)$ disagreed. With regard to the statement that time used for attending courses, conferences and workshops was taken from individual vacation days, 19 (49\%) respondents disagreed with it, and 19 (49\%) gave no opinion, whilst 1 (2\%) agreed. According to Wen (2005):

an organisational culture for sharing of knowledge and expertise should be established with appropriate rewards and incentives. Those staff members who share their tacit knowledge and experiences through writing, publishing, lecturing, tutoring, or mentoring should be appropriately recognised and rewarded. (n.p.)

Information flow was suggested in KM literature as the way knowledge could travel and grow within an organisation. Koenig (2003) credits the flow of formal and informal information up, down and across the enterprise as the source for improvements in operational productivity. Similarly, knowledge flow also requires a working environment that nurtures and accelerates the sharing of knowledge. Responding to the question of the impact of knowledge sharing on individuals, questionnaire respondents felt that it enabled their quick accomplishment of tasks as evidenced by $29(71 \%)$ who agreed, whilst $5(12 \%)$ gave no opinion, and 7 (17\%) disagreed. They also felt that it improved their job performance as highlighted by $30(73 \%)$ who agreed, whilst 6 (15\%) were non-committal, and 5 (12\%) disagreed. Amongst the respondents, $30(73 \%)$ agreed that knowledge sharing was generally useful in their jobs, whilst $8(20 \%)$ seemed ambivalent, and $3(7 \%)$ disagreed with that perception. Table 5 demonstrates these perceptions.

Questionnaire responses indicated that knowledge sharing enabled individuals to react more quickly to change:

- $28(68 \%)$ agreed with this statement

- $9(22 \%)$ gave a non-committal response

- $4(10 \%)$ disagreed.

All interview participants shared the view that information and knowledge sharing had the potential to turn individual knowledge into organisational knowledge for the College. Thus a curriculum-related symposium held at MCNY in 2009 and mentioned in interviews could be significant as a KM technique since it was intended to create an information transfer and sharing platform for faculty, the library and the rest of the college. These data suggest that knowledge sharing was viewed at MCNY as important in job performance, and imply that the potential to benefit from using KM tools and techniques that enabled retaining knowledge for subsequent re-use did exist.

The capability of individuals to operate in ways that enable $\mathrm{KM}$ practice is expressed by responses to the question whether knowledge sharing in the departmental environment
TABLE 5: Environment for sharing of knowledge and the individual in a department.

\begin{tabular}{|c|c|c|c|c|c|c|}
\hline \multirow{2}{*}{$\begin{array}{l}\text { Employees' experience of knowledge } \\
\text { sharing }\end{array}$} & \multicolumn{2}{|c|}{ Agree } & \multicolumn{2}{|c|}{ Neutral } & \multicolumn{2}{|c|}{ Disagree } \\
\hline & $n$ & $\%$ & $n$ & $\%$ & $n$ & $\%$ \\
\hline Enables me to accomplish tasks quickly & 29 & 71 & 5 & 12 & 7 & 17 \\
\hline Improves my job performance & 30 & 73 & 6 & 15 & 5 & 12 \\
\hline Useful in my job overall performance & 30 & 73 & 8 & 20 & 3 & 7 \\
\hline $\begin{array}{l}\text { Enables me to react more quickly to } \\
\text { change }\end{array}$ & 28 & 68 & 9 & 22 & 4 & 10 \\
\hline
\end{tabular}

change

$n$, number of responses

was seen as facilitating knowledge storage. Twenty-one (51\% respondents agreed, 14 (34\%) gave a non-committal response, and $6(15 \%)$ disagreed. The question whether knowledge sharing in the departmental environment facilitated knowledge retrieval had 27 (66\%) agreeing, 9 (22\%) giving no opinion, and 5 (12\%) disagreeing; whilst the question whether knowledge sharing in that environment facilitated knowledge transfer had 31 (75\%) agreeing, 6 (15\%) giving no opinion, and $4(10 \%)$ disagreeing. There was also the perception that it speeded up decision making: 28 (68\%) agreed that it did, $8(20 \%)$ gave a non-committal response, and $5(12 \%)$ disagreed. The importance of knowledge sharing was corroborated by all interview participants. However, only $14 \%$ of observable events recorded could be categorised as knowledge sharing, suggesting that at MCNY, acknowledging that sharing was important may only have had a marginal relationship to actual sharing.

\section{Knowledge Management-related issues and challenges at Metropolitan College New York}

For Metropolitan College New York (MCNY) the main issues and challenges related to KM are:

- database and information systems need to be clearly organised

- except in classrooms, faculty have limited occasions for sharing knowledge

- a scientific approach to creating knowledge is needed

- it is important to encourage initiatives to use already created knowledge

- an awareness of the weaknesses of non-knowledge-based activities has to be created

- a proper organisational structure to create and transfer knowledge is necessary

- motivation programmes and encouragement to create and use knowledge need to be in place at MCNY.

\section{The reasons for Knowledge Management initiatives in educational institutions}

Educational institutions such as the MCNY are the best places for advancing KM initiatives for the following reasons:

- Students need to be aware of the benefits that are possible from a sound teaching-learning environment. That encourages them to market the College, enhancing student enrolment and retention in the process.

- Research knowledge and skills within different College departments can be shared systematically, which will enable creativity, particularly as it is likely that different 
types of knowledge assets have differing influences on knowledge creation.

- The enhanced use of technology that is already in place can expedite the dissemination and sharing of knowledge.

- Networking activities within and outside the College can propagate healthy relations with the community and potential employers for its graduates.

\section{Encouraging the implementation of Knowledge Management initiatives at Metropolitan College New York}

The large number of part-time faculty and the slow hiring of new full-time faculty at MCNY can have an impact on the morale of those in the teaching area of the institution. It also makes it complicated to implement a system of regular measurement and accountability, and as a result teaching and research performance becomes difficult to measure. For this reason there are few incentives to perform. The following factors may encourage KM initiatives in the future:

- An open institutional culture is required with incentives to promote the integration of individual skills and experiences into institutional knowledge.

- It is important to recognise the many strengths of knowledge utilisation formally and informally.

- It is necessary to recognise that it is not only technology that supports KM activities. Social relations, networking and interaction are some of the main elements that arise from KM practices.

- There is a need to constantly bring new knowledge into the institution, and use it to enhance the MCNY experiential model of teaching and learning.

- Encouraging people to communicate with one another and share their ideas is essential.

\section{Prerequisites to implement Knowledge Management initiatives at Metropolitan College New York}

$\mathrm{KM}$ is a multidisciplinary and trans-disciplinary field and does not have prescriptive implementation methodologies. However, prior to implementing KM initiatives the following initial steps should be taken:

- To become aware of a KM strategy at MCNY, an assessment of the current situation needs to be carried out by highlighting existing KM activities and experience, outlining the benefits, explaining how these can be built upon, and exposing barriers to further progress. This will show how current KM practice (or lack of it) affects the ability of the staff in various departments to meet intended goals and will demonstrate the connection between faculty, staff, students and other institutions.

- It is essential to map the stock of knowledge at MCNY. Identifying expertise enables the College to push the sharing of best practices. This can be done by examining the performance results of faculty and staff. If best practices and styles are already in place, it is better to use them to enhance performance rather than attempting to invent new ways. Jain (2007:379) suggests a mapping knowledge or knowledge gap exercise: 'Knowledge mapping can identify organisational knowledge assets as well as knowledge gaps'. This exercise helps in the eventual measuring of the effectiveness and success of implementing KM tools and principles.

- The people who need knowledge at MCNY should be identified. It is very important to focus on mission-critical rather than just fashionable knowledge practices.

- It is important for institutional members to have easy access to knowledge. Manuals, instructions, catalogues, notices, computer facility and databases help in making knowledge visible so that it can be transferred easily around the MCNY and enable departments to use such knowledge for planning and making decisions.

- A policy to institutionalise KM initiatives should be developed. It is necessary to facilitate knowledge growth through institutional culture and incentives. Incentives can help to reinforce best practices, and at the same time to instil a shift in behaviour. Incentives can be based on an annual performance review on the basis of employee contribution to the institution's knowledge.

\section{Summary and conclusions}

The study established that motivation programmes to create and use knowledge was nonexistent at MCNY. Furthermore, research knowledge and skills within different College departments were not shared systematically, thereby enabling creativity and knowledge creation. In the KM-based society of the 21st century an organisation that fails to manage knowledge finds it difficult to sustain and grow its activities. It would benefit MCNY to move towards organisational efforts to create and share knowledge systemically and systematically. The plan to use KM practices implies the need to understand the context that different types of knowledge requires, as well as organising information (re-packaging it) in the manner most useful to the College community, particularly in an information environment that uses social networking functionalities extensively. It becomes possible to learn from previous experiences and situations, and be able to anticipate the specific requirements of MCNY.

At MCNY, establishing and maintaining a strong technological base focusing on the intended teachinglearning environment and promoting research activities, and creating and organising technology-based knowledge and knowledge-based networking are essential initiatives. Additionally $\mathrm{KM}$ practices need to be tapped from institutional skills and the already existing intellectual capital. A supportive institutional climate can therefore bring systemic transformation to the entire institution.

\section{Acknowledgements}

\section{Competing interests}

The authors declare that they have no financial or personal relationship(s) which may have inappropriately influenced them in writing this paper. 


\section{Authors' contributions}

J.M. (Zayed University) and P.N. (University of South Africa) conceptualised the study together. J.M. (Zayed University) designed the study and collected some of the data that the study reports as part of her doctoral studies. P.N. (University of South Africa) converted the study into a publishable journal article and dealt with the comments of the reviewers and the editors.

\section{References}

Aharony, N., 2011, 'Librarians' attitudes towards knowledge management', College \& Research Libraries 72(2), 111-126.

Aswath, L. \& Gupta, S., 2009, 'Knowledge management tools and academic library services', International Conference on Academic Libraries - vision and roles of the future academic libraries, Delhi, India, October 05-08, 2009, pp. 187-192.

Bailey, C.W., 2005, 'The role of referencelibrariansin institutional repositories', Reference Services Review 33(3), 259-267. http://dx.doi.org/10.1108/00907320510611294

Barquin, R., 2001, 'What is knowledge management? Knowledge and innovation', Journal of the $\mathrm{KMCl} 1(2), 127-143$.

Branin, J.J., 2003, 'Knowledge management in academic libraries: Building the knowledge bank at the Ohio State University', Journal of Library Administration 39(4), 41-56. http://dx.doi.org/10.1300/J111v39n04_05

Broadbent, M., 1998, 'The phenomenon of knowledge management: What does it mean to the information profession? Knowledge management: An emerging
concern', viewed 24 January 2008, from http://www.sla.org/pubs/serial/io/1998/ concern', viewed 24 Jan
may98/broadben.html

Chou, S.W. \& He, M.Y., 2004, 'Facilitating knowledge creation by knowledge assets', viewed 20 January 2008, from http://ieeexplore.ieee.org/xpl/articleDetails. jsp?arnumber=1265584. http://dx.doi.org/10.1109/HICSS.2004.1265584

Cohen, A., 1989, The service society and a theory of learning linking education, work and life, Audrey Cohen College, New York.

Creswell, J.W., 2007, Qualitative inquiry and research design: Choosing among five approaches, Sage, Thousand Oaks, CA.

Gandhi, S., 2004, 'Knowledge management and reference services', The Journa of Academic Librarianship 30(5), 368-381. http://dx.doi.org/10.1016/j. acalib.2004.06.003

Hernon, P. \& Schwartz, C., 2007, 'What is a problem statement?', Library \& Information Science Research 29, 307-309. http://dx.doi.org/10.1016/j.lisr.2007.06.001

Jain, P., 2007, 'An empirical study of knowledge management in academic libraries in East and Southern Africa', Library Review 56(5), 377-392. http://dx.doi. org/10.1108/00242530710750572

Kidwell, J.J, Vander Linde, K.M \& Johnson, S.L., 2000, 'Applying corporate KM practices in higher education', Educause Quarterly 4, 28-33.

Kim, Y-M. \& Abbas, J., 2010, 'Adoption of library 2.0 functionalities by academic libraries and users: A knowledge management perspective', The Journal of Library and Information Studies, 36(3), 211-218.

Koenig, M., 2003, 'Knowledge management, user education and librarianship', Library Review 52(1), 10-17. http://dx.doi.org/10.1108/00242530310456979
Kok, J.A., 2003, 'Role of leadership in the management of corporate knowledge', South African Journal of Information Management 5(3), viewed 19 July 2012, from http://www.sajim.co.za/index.php/SAJIM/article/view/363/353

Kok, J.A., 2012, 'Knowledge management @ DoTPW', paper presented to the International Knowledge Conference at the University of Stellenbosch Business School, Stellenbosch, 16-18 January, viewed 19 July 2012, from http://www. usb.ac.za/Common/Pdfs/KnowledgeManagementConference/JKok_KnowledgeManagement_Department-of-Transport-and-Public-Works.pdf

Mavodza, J. \& Ngulube, P., 2011, The use of knowledge management tools and techniques in library practices in an academic environment', Mousaion 29(2) 94-115.

MCNY Self-Study, 2009, Self-study for Middle States Commission on Higher Education: Comprehensive accreditation review, MCNY, New York.

Nonaka, I. \& Konno, N., 1998, 'The concept of "Ba": Building a foundation for knowledge creation', California Management Review 40(3), 40-50.

Nonaka, I. \& Takeuchi, H., 1995, The knowledge-creating company: How Japanese companies create the dynamics of innovation, Oxford University Press, New York, NY.

Nonaka, I. \& Teece, D.J., 2001, 'Research directions for knowledge management', in I. Nonaka \& D.J. Teece (eds.), Managing industrial knowledge: creation, transfer and utilization, pp. 330-335, Sage, London. http://dx.doi. org/10.4135/9781446217573.n17

Nonaka, I., 1991, 'The knowledge-creating company', Harvard Business Review 69(6), 96-104.

Rowley, J., 2003, 'Knowledge management - the new librarianship? From custodians of history to gatekeepers to the future', Library Management 24(8/9), 433-440. http://dx.doi.org/10.1108/01435120310501112

Senge, P.M., 1994, The fifth discipline: The art and practice of the learning organization, Doubleday, New York.

Singh, M.D. \& Kant, R., 2008, 'Knowledge management barriers: an interpretive structural modelling approach', International Journal of Management Science \& Engineering Management 3(2), 141-150.

Singh, S.P., 2007, 'What are we managing - knowledge or information?', VINE: The Journal of Information \& Knowledge Management Systems 37(2), 169-179.

Stake, R.E., 2005, 'Qualitative case studies', in N.K. Denzin \& Y.S. Lincoln (eds), The Sage handbook of qualitative research, pp. 121-135, Sage, Thousand Oaks, CA.

Stankosky, M.A., 2005, 'Advances in knowledge management: University research toward an academic discipline', in M. Stankosky (ed.), Creating the discipline of knowledge management: The latest in university research, $\mathrm{pp} .1-14$, ButterworthHeinemann, Burlington, MA. http://dx.doi.org/10.1016/B978-0-7506-7878$0.50005-3$

Tellis, W., 1997, 'Application of a case study methodology', The Qualitative Report 3(3), viewed 03 February 2008 from http://www.nova.edu/ssss/QR/QR3-3/tellis2.html

Townley, C.T., 2001, 'Knowledge management and academic libraries', College \& Research Libraries 62(1), 44-55.

Weddell, S., 2008, 'Transforming reference into a proactive knowledge advisory service: A case study', Reference Services Review 36(2), 147-155. http://dx.doi. org/10.1108/00907320810873011

Wen, S., 2005, 'Implementing knowledge management in academic libraries: A pragmatic approach', Chinese Librarianship: An International Electronic Journal 19, viewed 04 December 2009, from http://www.white-clouds.com/iclc/cliej/ cl19.htm

Williams, A., Giuse N., Koonce, T., Kou, Q. \& Giuse, D., 2004, 'Using knowledge management practices to develop a state-of-the-art digital library', Medinfo 11(1), 99-103. 